\title{
Cloning and Characterization of Two Phosphate Transporters from Medicago truncatula Roots: Regulation in Response to Phosphate and to Colonization by Arbuscular Mycorrhizal (AM) Fungi
}

\author{
Henry Liu, Anthony T. Trieu, Laura A. Blaylock, and Maria J. Harrison \\ The Samuel Roberts Noble Foundation, Plant Biology Division, 2510 Sam Noble Parkway, Ardmore, OK \\ 73402, U.S.A. \\ Accepted 10 September 1997.
}

\begin{abstract}
Most vascular plants can acquire phosphate from the environment either directly, via the roots, or indirectly, via a fungal symbiont that invades the cortical cells of the root. Here we have identified two cDNA clones (MtPT1 and MtPT2) encoding phosphate transporters from a mycorrhizal root cDNA library (Medicago truncatula/Glomus versiforme). The cDNAs represent $M$. truncatula genes and the encoded proteins share identity with high-affinity phosphate transporters from Arabidopsis, potato, yeast, Neurospora crassa, and an arbuscular mycorrhizal (AM) fungus, $G$. versiforme. The function of the protein encoded by MtPT1 was confirmed by complementation of a yeast phosphate transport mutant (pho84). The $K_{m}$ of the MtPT1 transporter in this system is $192 \mu \mathrm{M}$. MtPT1 and MtPT2 transcripts are present in roots and transcript levels increase in response to phosphate starvation. MtPT transcripts were not detected in leaves. Following colonization of the roots by the AM fungus $G$. versiforme, both MtPT1 and MtPT2 transcript levels decrease significantly. Down-regulation of phosphate starvation-inducible genes in mycorrhizal roots appears to be a common occurrence and a homologue of a phosphate starvation-inducible purple acid phosphatase is also down-regulated in the mycorrhizal roots. The functional characteristics and expression patterns of the MtPT transporters are consistent with a role in the acquisition of phosphate from the environment but suggest that they may not be involved in phosphate uptake at the symbiotic interface in mycorrhizal roots.
\end{abstract}

Additional keywords: multigene family, symbiosis.

Phosphate is an essential mineral nutrient for plant growth and development; however, the mechanisms of phosphate uptake, transport, and utilization by plants are still largely unknown. Physiological measurements of phosphate uptake in plant cells indicate the presence of a number of transport sys-

Corresponding author: Maria J. Harrison; Telephone: 405223 5810; Fax: 405221 7380; E-mail: mjharrison@ @oble.org

Nucleotide and/or amino acid sequence data are to be found at GenBank as accession numbers AF000354 and AF000355. tems, which operate optimally over different phosphate concentration ranges (Shimogawara and Usuda 1995; Nandi et al. 1987; Furihata et al. 1992). Phosphate transporters have been cloned recently from the roots of two plant species, Arabidopsis thaliana (Muchhal et al. 1996; Smith et al. 1997) and potato (Solanum tuberosum) (Leggewie et al. 1997). Expression studies in yeast (Saccharomyces cerevisiae) indicate that the potato cDNAs encode active transporters and probably operate by proton-coupled symport (Leggewie et al. 1997). This is also the mechanism by which the fungal high-affinity transporters operate (Beever and Burns 1980; Bun-ya et al. 1991). Recent investigations of phosphate transport in yeast suggest that high-affinity phosphate uptake is mediated by a multicomponent system. Four additional gene products, Gtrlp, PHO86, PHO87, and PHO88, that interact with the PHO84 transporter are implicated in this process (Bun-ya et al. 1992, 1996; Yompakdee et al. 1996a, 1996b). Based on the current understanding of the similarities between the fungal and plant systems, it is possible that the plant phosphate uptake systems also involve other components.

The range of phosphate concentrations that plant roots encounter in the soil is extremely broad. Phosphate levels are occasionally as high as $10 \mu \mathrm{M}$ but more frequently as low as 1 $\mu \mathrm{M}$ (Marschner 1995). In addition, phosphate is relatively immobile in the soil and absorption by the roots results in a localized depletion zone containing even lower levels of phosphate (Marschner 1995). Consequently, plants have evolved a range of mechanisms to access phosphate from low nutrient environments, one of the most widespread being the formation of symbiotic associations with arbuscular mycorrhizal (AM) fungi, which assist them with phosphate uptake from the soil (Harley and Smith 1983; Smith and GianinazziPearson 1988). The AM symbiosis occurs in the majority of terrestrial plant species and has its origins as far back as the Devonian period, coincident with the emergence of terrestrial plants (Simon et al. 1993; Remy et al. 1994). In this association, the fungi colonize the cortex of the root but also maintain a network of hyphae that extend out of the root into the surrounding environment. These external hyphae access phosphate from the soil and transfer it to the plant root (Sanders and Tinker 1971; Smith and Gianinazzi-Pearson 1988). A high-affinity phosphate transporter, likely to be responsible for 
this initial phosphate uptake, has recently been cloned from the AM fungus $G$. versiforme (Harrison and van Buuren 1995). Inside the root, the fungi grow both inter- and intracellularly and the intracellular arbuscules probably function in nutrient exchange with the plant. The mechanisms of phosphate transfer from the fungus to the plant are currently unknown. However, the process is generally assumed to occur over the arbuscule/cortical cell interface, and active transporters are predicted to be present on the plant plasma membrane at the interface to transport phosphate into the cortical cell (Smith and Smith 1989, 1990, 1996). Thus, in a mycorrhizal root, which is the predominant situation for plants in natural ecosystems, an additional pathway of phosphate entry into the roots is functioning. Whether or not the phosphate transporters operating in the cortical cells at the symbiotic interface are the same as those in the nonmycorrhizal root is currently unknown.

To investigate the molecular processes of phosphate transport in plant roots prior to, and during, mycorrhizal associations, it is necessary to clone the transporters from a system suitable for the study of the mycorrhizal symbiosis. As $A$. thaliana does not form these associations, we have selected $M$. truncatula, a model legume, as a host plant for molecular and genetic studies of the AM symbiosis (Harrison 1996). Here we report the cloning of two phosphate transporters from $M$. truncatula and the characterization of their expression patterns in nonmycorrhizal and mycorrhizal roots.

\section{RESULTS}

\section{Cloning of MtPT1 and MtPT2, two members}

of a small multigene family of phosphate transporters in M. truncatula.

An A. thaliana expressed sequence tag (EST) clone (stock no. 134M11T7) that shares identity with three known phosphate transporter genes from G. versiforme, S. cerevisiae, and N. crassa (Bun-ya et al. 1991; Harrison and van Buuren 1995; Versaw 1995) was used as a probe to screen a mycorrhizal root cDNA library prepared from $M$. truncatula/G. versiforme root RNA (M. L. van Buuren, A. T. Trieu, L. A. Blaylock, and M. J. Harrison, unpublished). This resulted in the identification of a cDNA clone (MtPT1) that shares sequence identity with the EST. MtPT1 contains an insert of 1,942 bp, including a poly $\mathrm{A}^{+}$tail at the $3^{\prime}$ end, and is predicted to contain an open reading frame of 537 amino acids (GenBank accession number AF000354).

Part of the MtPT1 cDNA (1 to 1,386 bp) was used as a probe and hybridized under high-stringency conditions to a Southern blot of M. truncatula genomic DNA. This analysis indicated that MtPT1 represents a member of a small multigene family containing two or possibly three highly similar genes (Fig. 1). Following this analysis, the MtPT1 coding sequence was used as a probe to further screen mycorrhizal root (M. truncatula/G. versiforme) and $M$. truncatula root cDNA libraries, and an additional 18 clones were identified. Ten cDNA clones shared complete sequence identity with MtPT1. The other eight clones were identical to each other and shared high sequence identity with MtPT1 in the coding region, but contained significantly different $5^{\prime}$ and $3^{\prime}$ untranslated regions. The longest cDNA clone of this group, called MtPT2, was 1,897 bp in length with a predicted open reading frame of 533 amino acids (GenBank acces- sion number AF000355). A total of 19 cDNA clones sharing identity with either MtPT1 or MtPT2 were obtained and we suggest that two different phosphate transporter genes are expressed in M. truncatula root tissue.

\section{MtPT1 and MtPT2 share sequence identity with other phosphate transporters.}

MtPT1 and MtPT2 share $91.6 \%$ sequence identity at the nucleic acid level and the encoded proteins share $98 \%$ identity, with estimated molecular masses of 58.74 and $58.22 \mathrm{kDa}$, respectively. The proteins are extremely hydrophobic and are predicted to be integral membrane proteins containing 12 membrane-spanning domains. This is one of the classical membrane transporter protein secondary structures (Griffith et al. 1992; Marger and Saier 1993). Sequence searches of the GenBank data base indicate that MtPT1 and MtPT2 share 77 to $79 \%$ amino acid identity with two phosphate transporters from A. thaliana and two from Solanum tuberosum that were reported recently (Fig. 2) (Muchhal et al. 1996; Leggewie et al. 1997). Among the sequences conserved in these six transporters are the motifs MKMPETARYTA and PESKGKSLEELS, which are potential consensus sequences for phosphorylation by protein kinase $\mathrm{C}$ and casein kinase II, respectively (Fig. 2). The MtPT proteins share a much lower level of identity with the phosphate transporters from $G$. versiforme (Harrison and van Buuren 1995), S. cerevisiae (Bunya et al. 1991), and $N$. crassa (Versaw 1995), sharing 37.1, 29.7 , and $29.6 \%$ amino acid identity, respectively. However, it is interesting to note that the consensus sequences for phosphorylation are still conserved.

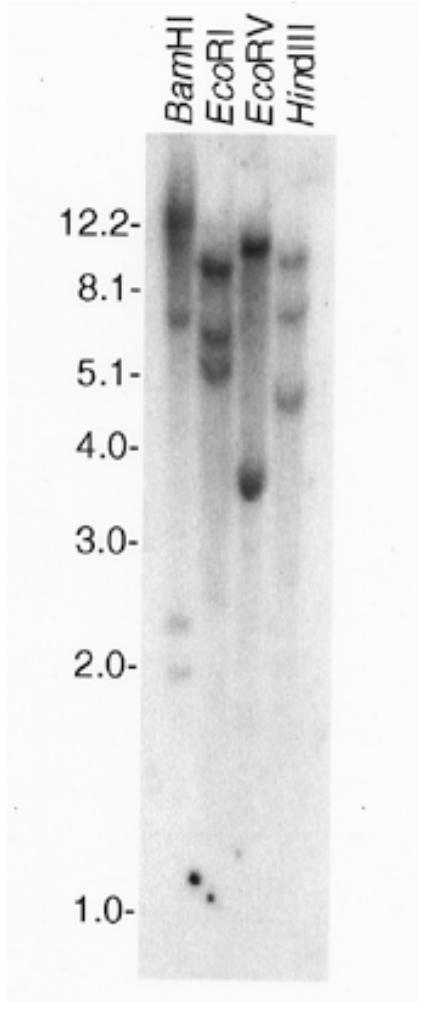

Fig. 1. Southern blot of Medicago truncatula genomic DNA hybridized with MtPT1. DNA was digested with BamHI, EcoRI, EcoRV, and HindIII. The size markers $(\mathrm{Kb})$ are shown to the left of the figure. 
Expression of MtPT1 in an S. cerevisiae phosphate transport mutant.

To determine whether MtPT1 encodes a functional phosphate transporter, the MtPT1 coding sequence was cloned into
MSGE---LGVLNALDVAKTQLYHETTIVIAGMG FFTDA YDLFCISLV'TKL,

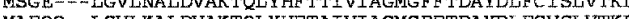

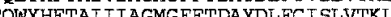
MAVEDMTO * $* * * * * * * * * * * * * * * * * * * * * * * * * * * * * * * * * *$

LGRIYYTEPNPTRPGTLPPSAQSAVTGVALVGTLAGOLFFG - -WLGDKLG LGRI Y YTTEPNPTR PGTLPPSAOSAVTGVALVGTLAGOLFFG - -WLGDKL LGRIYY YNPE SAKPGSLPPHVAAAVNGVAICGTLSGOLFFG -...WLGDKL LERIYYTVEGAOKPGTLPPNVAAAVNGVAFCGTLAGOLFFG--WLGDKILG 作 $\underset{* * * * * *}{\text { LGRLYYTRPDLLPGTLPPARVGLRHGCALVGTLAGQLFFGCARLA }- \text { KMG }}$

RKKVYGLTLILMVVCSVGSGLSFGSSPKSVMATLCFFRFWLGFGIGGDYP RKKVYGLTLILMVVCSVASGLSFGSSPKSVMATLC FFRFWLGFGIGGDYP RKKVYGLTL VMMILCSVASGLSFGHEAKGVMTTLCFFRFWLGFGIGGDYP RKKVYGMILMVMVLCSIA SGLSFGHEPKAVIATILCFFRFWLGFGIGGDYP RKKVYGMTLMIMVICSIASGLSFGHTPKSVMTTLCFFRFWLGFGIGGDYP RKKVYGMTLVLMWVCSVA SGLSLGNTPKVUNTTTLCFFRFWLGFGIGGDYP

LSATIMSEYANKKTRGAF IAAVFAMQGFGILGGGIVALIVASI FDHKYKV LSATIMSEYANKKTRGAF IAAVFAMOGFG ILGGGIVALTVASI FDHKYKV SATTMSEYANKKT RGAF IAAVFAMQGFGI IGGGIVALTVASIFDHKYKV LSATIMSEYANKKT'RGAF I AAVFAMQGVG ILAGGFVALAVSSIFDKKFPA LSATIMSEYANKK'T'RGAFVSAVFAMQGFGIMAGGIFAIIISSAFEAKFPS LSATIMSEYANKKTRGAFIAAVFAMCGFGILAGGMVAI IVSSAFKGAFPA LSATIM-EYANKKTRGAF IAAVFAMOGFGILFSGIVALITAAGFDHAYKA PTFEENPATSLLVPOFDYYWRI IIMFGALPARLTYYYRMKMPETARYTAI PTFEENPAASLLVPOFDYVWRLILMFGALPAALTYYWRMKMPETARYTAL PTYAVNRALST -PPQVDY IWR I IVMFGALPAALTYYWRMKMPETARYTAL PAYADD-ALGSTIPOADLVWRIILMAGAI RAAMTYYSRSKMPETARYTAL P-YEVD-ALASTVSOADFVWRI I LMFGAI PAGLTYYWRMKMPETARYTAL PTFAENAAVST-VPQADY IWRI ILMFGSLPAALTYYWRMKMPETARYTAL VAKNAKOAAADMSKVLQVELEVEEEKVOKMTSDKR-NSYGLFSKQFAARH VAKNARQAAADMSKVLQVELEVEEEKVEKMTSDKR-NSYGLFSKOFAARH VAKNIKRATADMSK VLQTDIELE -RVEDDVDPK - QNYGLFSKEFLRRH AKRK VAKDARRAAQDMGRVLQVEIESEEAKI EQI SRDE-TNQFGLFSWEFVRRF GLALF GTCSTWFLLDIAFY SQNLFOKDIFSAIGWIPPAKEMNAIHEVYKI

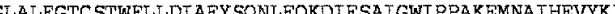
GLALL TC STFL DTAFY SONL FOKDIFSATGWT PKAATMNATHEVFRT GLHELGTTSTWFI DTAFY SONL FOKDTFSAIGWI PPAOSMNATOFVFK GLHLLGTA ST WFLEDTAFY SONLFOKDI F SAIGWTPPAOTMNAI.EEVYK I GEFLFGTCSTWFLLDIAFY SQNLEQKDVF SAVGWT PKAPTMNAVQELLYKI

ARAQT LIALC STVPGYWFTVAFIDHMGRFAIQMMGFFFMTVFMFGLAIPY ARAQTLIALC STVPGYWETVAF IDHMGRFAIQMMGFFFMTVFMF ALAIPY ARAQTLIALCSTVPGYWFTVAF IDTIGRFKIQLNGF FMMTVFMFAIAFPY ARAQTL IALC STVPGYWETVA IDVIGRFA IQMMG FEFMTVFMFALATPY ARAQTLIALC STVPGYWFTVAFIDRIGRFA IQLMG FFFMTVFMFALALPY ARAQTLIALCSTVPGYWFTVAFIDIIGRFAIQLMGFFFMTVFMFATAIPY DHWSKEENRIGFVVYYSLTFFF SNFGPNAATFVVPAEI FPARLRSTCHGI DHWSKEENRIGFVVIYSLTE'FEANFGPNAT'TEVVPAEI FPARLRSTCHGI NHWIKPENRIGFVWY SLTEF FANFGPNAT TF IVAEI FPARLRSTCHGI 作 HHWTL KDNRIGFVVMY SLTEFFANFGPNATTFVVPAEI FPARLRSTCHGI HHWTLEANRIGFIVMYSLTEFFANFGPNATTFVVPAEIFPARLRSTCHGI

SAAAGKAGAIVGAFGFLYAAQSKDPTKTDKGYPTGIGIKNSLTMLGVINF SAAAGKAGAIVGAFGFLYAAOSKDPTKTDKGYPTGIGTKNSLTMLGVIN SAAAGKAGAIVGAFGF LYAAQSODKAXVDAGYPPGIGVKNSLIMLGVLNF SAASGKLGAMVGA FGFLYLAONPDKDKTDAGYPPGIGVRNSLIVLGVVN SAAAGKAGAMVGAEGFLYAAOPTDPKKTDAGY PAGIGVRNSLIVLGCVN SAAAGKAGAIVGA YGF LYAAOSKDPMKTDAGYPAGIGIKNSLTVLGFINA VGLCTLLVP ESKGKSLEELSGENEGEGAEATEQEGPRFENVA-VGMLCTLLVPESKGKSLEEL_SGENEGEGAEAAEQEGSR-- - -V---

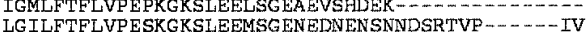
LGILFTFLVPESKGKSLE EMSGENEDNLNSNMDSRTVP-2-.--1V LGMLFTELVPESKGKSLEEMSRENEGEEETVAEMRATSGRTVLFK LGMVCTFCVPESKGKSLEEASQETISTGEA

Fig. 2. Alignment of the predicted amino acid sequences of MtPT1 and MtPT2 with amino acid sequences of the Arabidopsis transporters AtPT1 (U62330) and AtPT2 (U62331) and the potato transporters StPT1 (X98890) and StPT2 (X98891). “*” indicates identical amino acids; “." indicates similar amino acids. Overlined sequence is consensus sequence for phosphorylation by protein kinase $C$; double overlined sequence is consensus sequence for phosphorylation by casein kinase II. an $S$. cerevisiae expression vector (pAAH5) under the control of the alcohol dehydrogenase I promoter. The construct was transferred to an S. cerevisiae pho84 mutant (NS219) that is defective in phosphate uptake from low phosphate media due to a point mutation in the PHO84 gene. NS219 expressing MtPT1 displayed a significantly higher rate of phosphate uptake than the control NS219 line carrying the vector, indicating that MtPT1 encodes a functional phosphate transporter (Fig. 3). Further studies indicated that uptake follows Michaelis-Menton kinetics (Fig. 4) and MtPT1 has an apparent $K_{m}$ of $192 \mu \mathrm{M}$ and $V_{\max }$ of $955 \mathrm{pmol} / \mathrm{min}$ (per absorbance unit of cells).

A high-affinity phosphate transporter from G. versiforme (GvPT) has been analyzed previously in this yeast expression system (Harrison and van Buuren 1995). A direct comparison of phosphate uptake by the NS219 line expressing the MtPT1 and GvPT transporters revealed that, under low phosphate conditions, the NS219 line expressing GvPT displayed significantly higher phosphate uptake activity. Phosphate uptake in the NS219 line expressing MtPT1 was approximately $30 \%$ of that obtained in the NS219 line expressing GvPT (Fig. 3).

\section{MtPT1 and MtPT2 are regulated in response to phosphate.}

Previous physiological studies have indicated that phosphate uptake activity in plant roots and cell suspension cultures increases in response to phosphate starvation (Cogliatti and Clarkson 1983; Dunlop and Gardiner 1983; Clarkson and Lüttge 1991). To determine whether the expression of the MtPT genes is regulated in response to differing levels of phosphate in the environment, $M$. truncatula plants were

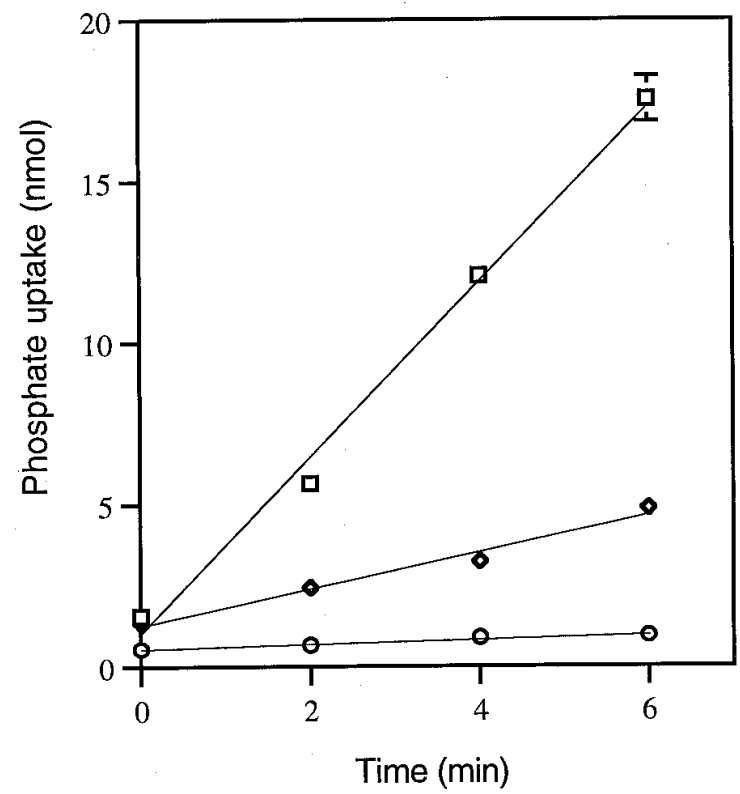

Fig. 3. Comparison of phosphate uptake in the yeast mutant line NS219 transformed with pAAH5 (vector control) (circle), MtPT1 (diamond), and GvPT (square). Uptake values are nmol phosphate in $500 \mu \mathrm{l}$ of yeast cell suspension with an absorbance of 1 unit at $600 \mathrm{~nm}$. Error bars represent standard error of the mean. In most samples, error bars were too small to be displayed on the graph. Phosphate uptake in NS219 carrying MtPT1 and pAAH5 differs significantly, with a probability of $<0.001$. (Student's $t$ test with data at 6-min timepoint.) 
grown for 40 days in sand and fertilized with half-strength Hoagland's solution containing increasing concentrations of phosphate between 0 and $5 \mathrm{mM}$. The plants displayed visual symptoms consistent with the different fertilization regimes, and phosphate analyses confirmed that the root and shoot tissues contained increasing levels of phosphate. RNA was extracted from the root and leaf tissue and the expression of MtPT1 and MtPT2 analyzed by Northern (RNA) blot analysis. Due to the high sequence identity between MtPT1 and MtPT2, hybridization with the full-length MtPT1 cDNA reveals the combined transcript levels of both transporters. As shown in Figure 5, the transcript level of the phosphate transporters is high in the roots of plants grown at $0,0.01$, and 0.2

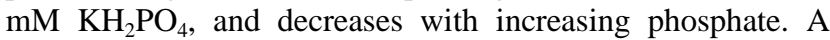
comparison of the normalized MtPT transcript levels revealed that MtPT transcripts were 4.5 -fold higher in the $0 \mathrm{mM}$ sample, compared with the level in the $5 \mathrm{mM}$ treatment. Genespecific oligonucleotide probes, capable of discriminating between MtPT1 and MtPT2, indicate that there are differences in the expression patterns of the two genes. MtPT2 is more sensitive to increasing phosphate levels and the transcript level is significantly lower in the $0.1 \mathrm{mM}$ phosphate treatment and barely detectable in plants fertilized with 1 and $5 \mathrm{mM}$ phosphate. In contrast, MtPT1 transcripts show a modest decrease in the plants grown at 1 and $5 \mathrm{mM}$ phosphate (Fig. 5). The induction of transporter transcripts in response to phosphate starvation was also observed in seedlings grown in liquid cultures. In this system, the phosphate transporter transcripts increase at least fourfold following transfer to media lacking phosphate (Fig. 6). MtPT transcripts were undetectable in leaves from plants grown under the different phosphate fertilization regimes (data not shown).

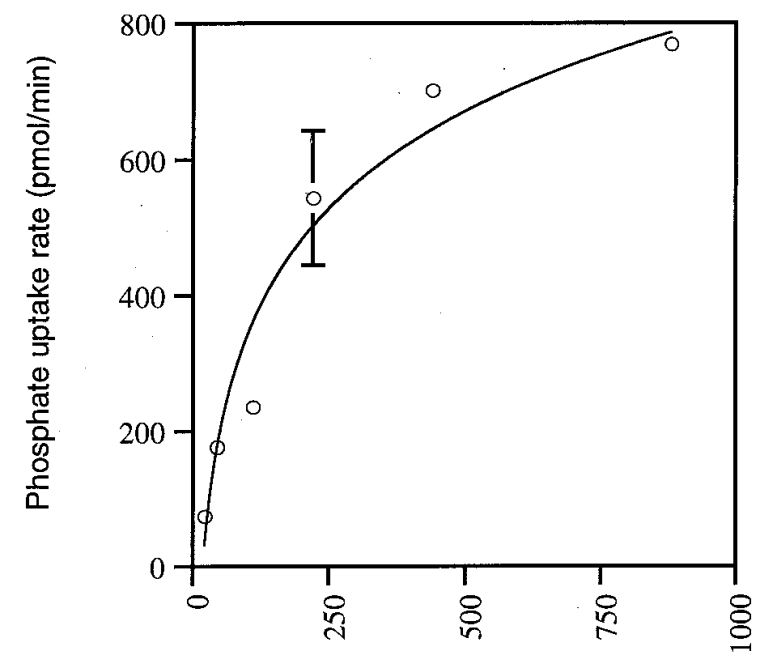

Phosphate concentration $(\mu \mathrm{M})$

Fig. 4. Phosphate uptake rate in the yeast line NS219 expressing MtPT plotted as a function of external phosphate concentration. Uptake values are nmol phosphate in $500 \mu \mathrm{l}$ of yeast cell suspension with an absorbance of 1 unit at $600 \mathrm{~nm}$. Data are the average of two independent experiments each with duplicate measurements. Error bars represent standard error of the mean. In most samples, error bars were too small to be displayed on the graph.

\section{Expression of MtPTs in M. truncatula roots colonized with the AM fungus $G$. versiforme.}

MtPT transcript levels were analyzed in M. truncatula roots during the development of an AM association with G. versiforme, to determine whether the expression patterns were consistent with a role for the transporters in phosphate uptake in the symbiosis. M. truncatula plants were inoculated with $G$. versiforme spores and plants were harvested at 8, 15, 22, 29, and 44 days after inoculation (dai). Mock-inoculated plants were included as controls. During the time course the M. truncatula roots were progressively colonized by the fungus and the colonization levels increased from $12 \%$ of the root length at 8 dai to $72 \%$ at 44 dai. Initially, at 8 dai, the colonization mostly consisted of fungal hyphae and appressoria growing on the external surface of the root. By 15 dai, internal colonization had begun and by 22 dai, and at subsequent timepoints, the majority of the colonization was internal, consisting of internal hyphae and arbuscules. Vesicles were present by 44 dai.

Total RNA was isolated from the colonized and control roots and the transcript levels analyzed by Northern blot analysis (Fig. 7). MtPT transcripts decreased in the control roots at 15 dai, but then increased slightly throughout the remainder of the time course. This is probably due to decreasing phosphate in the growth medium. In contrast, in mycorrhizal roots the transcript levels decreased throughout the time course. Transcript levels were 3.4-fold lower at 22 dai than at 8 dai, and were 4.2 -fold lower by 44 dai (Fig. 7). In comparison with the noncolonized control, the transcript levels in the colonized roots were 5.3-fold lower at 44 dai. The same

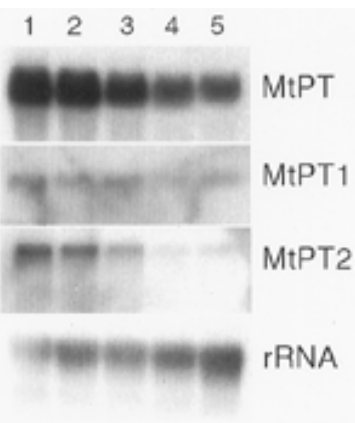

Fig. 5. Northern (RNA) blot of root total RNA $(6 \mu \mathrm{g})$ from Medicago truncatula plants grown under different phosphate regimes. Lanes 1 to

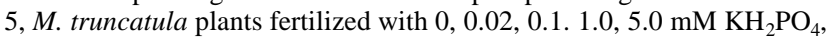
respectively. Blot was hybridized with MtPT (coding sequence probe) (top panel), MtPT1 oligo (second panel), MtPT2 oligo (third panel), and pSR1-2B3 (18S rRNA) (fourth panel) (Eckenrode et al. 1985).

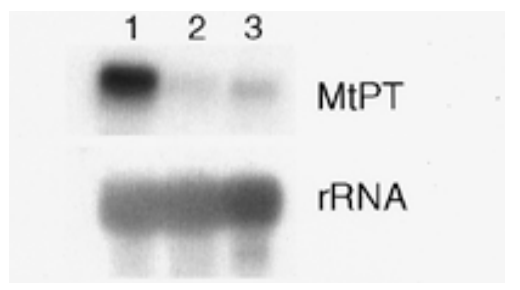

Fig. 6. Northern (RNA) blot of root total RNA (15 $\mu \mathrm{g})$ from Medicago truncatula seedlings grown in liquid media containing different levels of phosphate. $\mathrm{KH}_{2} \mathrm{PO}_{4}$ : lane 1, $0 \mathrm{mM}$; lane 2, $1.25 \mathrm{mM}$; lane 3, $2.5 \mathrm{mM}$. Blot was hybridized with the coding region of MtPT1 (upper panel) and pSR1-2B3 (18S rRNA) (lower panel) (Eckenrode et al. 1985). 
Northern blot was sequentially stripped and rehybridized with the specific oligonucleotide probes, revealing that both MtPT1 and MtPT2 show the same response to mycorrhizal colonization; transcripts levels for both genes decreased in mycorrhizal roots (Fig. 7).

By loading larger quantities of RNA from highly colonized root samples, the $G$. versiforme transporter (GvPT) transcripts can be detected while the MtPT transcripts decrease (Fig. 8). The GvPT transcripts are only expressed in the external hyphae, which constitute a very small percentage of the entire mycorrhizal root biomass, and consequently the transcripts can only be detected in the most highly colonized root samples.

\section{Down regulation of other phosphate starvation-inducible transcripts in mycorrhizal roots.}

To further determine whether other phosphate starvationinducible genes are down-regulated following mycorrhizal

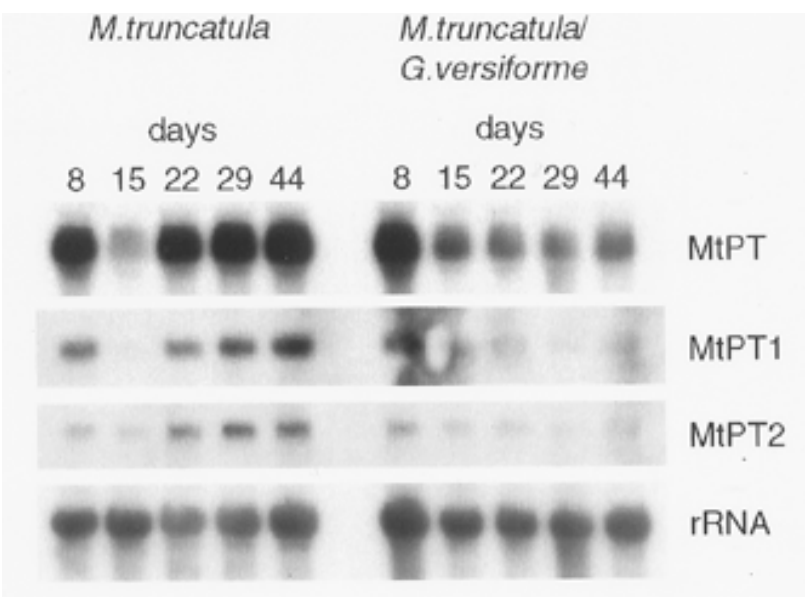

Fig. 7. Northern (RNA) blot of root total RNA $(6 \mu \mathrm{g})$ from Medicago truncatula and $M$. truncatula colonized with Glomus versiforme. Roots were inoculated at day 0 and harvested at 8, 15, 22, 29, and 44 days after inoculation. Controls were mock inoculated. Blots were hybridized with MtPT1 coding sequence probe, (top panel); MtPT1 oligo (second panel); MtPT2 oligo (third panel); and pSR1-2B3 (18S rRNA) (fourth panel) (Eckenrode et al. 1985). Numbers represent days after inoculation.

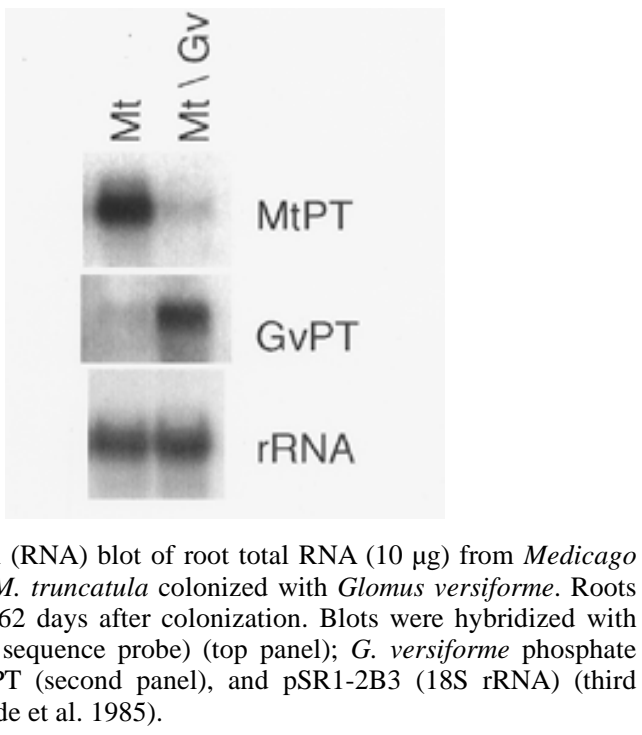

colonization, a cDNA clone encoding a secreted purple acid (PA) phosphatase from $A$. thaliana was used to probe the RNA from the mycorrhizal time course. The PA phosphatase clone is induced in response to phosphate starvation in $A$. thaliana (Patel et al. 1997). The cDNA hybridized to two transcripts of approximately 1.8 and $2.0 \mathrm{~kb}$ whose steady-state levels decreased following colonization (Fig. 9). The expression pattern was similar to those observed for the MtPTs. Transcripts were present in mycorrhizal roots at 8 dai but had decreased by 22 dai and remained at a low level throughout the remainder of the time course. The apparent increase at 44 dai is due to overloading, as indicated by the rRNA loading control. In addition, the transcript level in the colonized roots is lower than the levels in the noncolonized samples, which remain fairly constant throughout the time course.

\section{DISCUSSION}

As a first step to investigate molecular aspects of phosphate uptake in plant roots prior to, and during, the symbiotic association with mycorrhizal fungi, we have cloned two cDNAs encoding phosphate transporters from M. truncatula. The two clones share high sequence identity over the coding region but have divergent $5^{\prime}$ and $3^{\prime}$ untranslated regions, indicating that they represent two separate genes. The encoded proteins share high sequence identity ( 77 to $79 \%$ ) with the phosphate transporters cloned recently from A. thaliana and potato (Muchhal et al. 1996; Leggewie et al. 1997; Smith et al. 1997) and lower identity (29 to $37 \%$ ) with the fungal phosphate transporters (Bun-ya et al. 1991; Harrison and van Buuren 1995; Versaw 1995). Two regions conserved in all the phosphate transporters include sequences containing protein kinase $\mathrm{C}$ and casein kinase II phosphorylation sites. Regulation by phosphorylation has been reported for other transporters and channels (Lawrence et al. 1990; Johnson and Chrispeels 1992; Maurel et al. 1995), and the possibility that the phosphate transporters are also regulated in this way warrants further investigation.

On the basis of expression studies in a yeast high-affinity phosphate transport mutant (NS219), MtPT1 has been demonstrated to encode a phosphate transporter. The function of

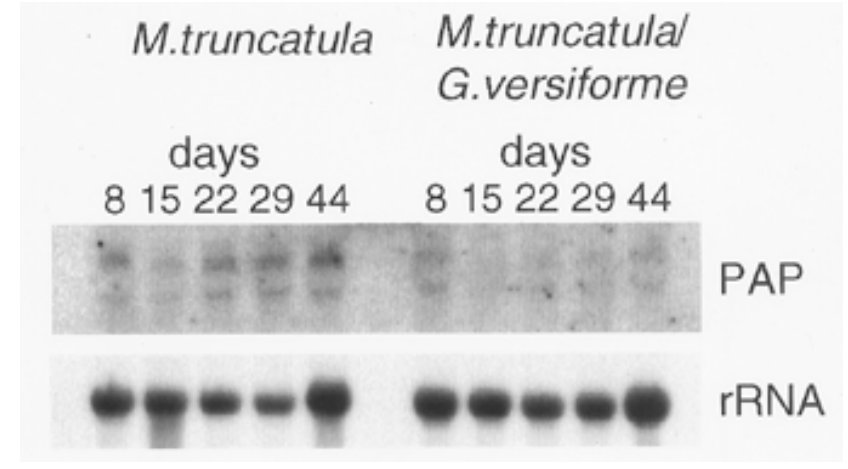

Fig. 9. Northern (RNA) blot of root total RNA $(6 \mu \mathrm{g})$ from Medicago truncatula and $M$. truncatula colonized with Glomus versiforme. Roots were inoculated at day 0 and harvested at 8, 15, 22, 29, and 44 days after inoculation. Controls were mock inoculated. Blots were hybridized with an Arabidopsis phosphate starvation-inducible purple acid phosphatase cDNA (PAP) (upper panel) and pSR1-2B3 (18S rRNA) (lower panel) (Eckenrode et al. 1985). Numbers represent days after inoculation. 
MtPT2 was not tested but, based on the high sequence identity with MtPT1 (98\%), it seems likely that it also encodes a phosphate transporter. Phosphate uptake measurements in NS219 expressing MtPT1 indicate that uptake follows Michaelis-Menton kinetics with an apparent $K_{m}$ of $192 \mu \mathrm{M}$. This is comparable to the $K_{m}$ values obtained for the Solanum tuberosum phosphate transporters expressed in yeast (Leggewie et al. 1997) but is much higher than the $K_{m}$ values of transporters from G. versiforme (GvPT) (Harrison and van Buuren 1995) and yeast (PHO84) (Bun-ya et al. 1991). It is also higher than the range of $K_{m}$ values obtained from studies of phosphate uptake in plant cells (Nandi et al. 1987; Shimogawara and Usuda 1995). A direct comparison of phosphate uptake in the NS219 lines expressing GvPT or MtPT1 indicated that phosphate uptake by MtPT1 was approximately $30 \%$ of that obtained for GvPT. Although it is interesting to speculate that the mycorrhizal fungal transporter might be more efficient than the plant transporter, it is also possible that the differences are due to expression in the heterologous system and not necessarily an intrinsic property of the transporters. Recent evidence indicates that phosphate uptake in yeast may require several proteins that interact to form a fully functional uptake system (Bun-ya et al. 1992, 1996; Yompakdee et al. 1996a, 1996b). MtPT1 shares a lower level of amino acid identity with PHO84 (32\%) than GvPT (48\%), and may interact less efficiently with the other components of the yeast phosphate uptake machinery. Similar arguments should be considered when comparing the $K_{m}$ values obtained from measurements in the heterologous system with those from intact plant cells.

Northern blot analyses indicate that the MtPT1 and MtPT2 genes are expressed in roots but not in leaves (data not shown). While both genes are induced in roots in response to phosphate deprivation, the patterns of expression are slightly different. MtPT2 is more responsive than MtPT1 to phosphate deprivation. This is similar to the expression patterns of the two transporters in potato (Leggewie et al. 1997). The expression patterns of the MtPTs and the A. thaliana and potato transporters are consistent with the phosphate starvationinducible, high-affinity phosphate uptake activity measured previously in plant roots and cell suspensions (Cogliatti and Clarkson 1983; Dunlop and Gardiner 1983; Clarkson and Lüttge 1991).

During the AM symbiosis, the fungal symbiont invades and differentiates within the cortical cells of the root to form arbuscules that are probably involved in phosphate release to the plant/fungal interface. Considerable modifications occur in the root cortical cells during this process, including an estimated three- to 10-fold increase in the plant plasma membrane, which extends to surround the hyphal branches of the arbuscule (Cox and Tinker 1976; Alexander et al. 1988). The molecular mechanisms of phosphate transfer across this membrane are unknown; however, cytochemical data support an active transport process (Gianinazzi-Pearson et al. 1991; Marx et al. 1982). It also seems reasonable to assume that the genes encoding transport proteins involved in this process will be up-regulated during the association to enable the proteins to be inserted into the newly developing membrane. Northern blot analyses were used to investigate expression of MtPT1 and MtPT2 during the development of a mycorrhizal symbiosis. Both MtPT1 and MtPT2 transcripts decrease following colonization of the plant by mycorrhizal fungus and the decline is initiated early in the colonization process. Consequently, it seems unlikely that these transporters are involved in phosphate transfer at the arbuscular interface. However, despite the decreased expression there are still MtPT transcripts present in mycorrhizal roots; further studies, including immunolocalization of the phosphate transporter proteins, will be necessary before a role in the symbiosis can be completely discounted.

While the expression patterns of MtPTs in mycorrhizal roots seem inconsistent with a role in phosphate transfer in the symbiosis, they are consistent with previous studies of the phosphate uptake in mycorrhizal roots. It was demonstrated that, in some cases, phosphate uptake from the soil by the roots becomes almost inactive in the mycorrhizal symbiosis. In these instances, initial phosphate uptake into the system is almost entirely due to uptake by the fungal hyphae (Pearson and Jakobsen 1993).

The down-regulation of a phosphate starvation-inducible gene in mycorrhizal roots was first observed for Mt4, a gene of unknown function from M. truncatula (Burleigh and Harrison 1997). MtPT1 and MtPT2 display similar expression patterns and we extended the analysis to include a phosphate starvation-inducible PA phosphatase. The $M$. truncatula homologue of this gene is also down-regulated following fungal colonization. The emerging pattern, that genes induced by phosphate starvation show down-regulation following colonization by the mycorrhizal fungus, is an interesting one. Initially, it might be assumed that increased phosphate delivered by the fungus is responsible for the down-regulation of these genes. However, studies of Mt4 expression in a mycorrhizal mutant suggest that, during the AM association, down-regulation of the Mt4 gene occurs in response to growth of the fungus on the root surface, prior to a stage at which phosphate transport is occurring, thus implying the existence of a second, "mycorrhiza-specific" signaling pathway for down-regulation of the Mt4 gene (Burleigh and Harrison 1997). Studies of the phosphate transporters and acid phosphatase gene expression in the mutant will help to determine whether this dual regulation is a general phenomenon of the phosphate starvation-inducible genes or a specific characteristic of the Mt4 gene.

Cloning and characterization of the MtPTs has provided the first molecular information on phosphate transport in legume roots and also preliminary evidence to suggest that phosphate transport during the AM symbiosis may not involve the phosphate starvation-inducible transporters functioning in nonmycorrhizal roots. These cDNA clones will enable future immunolocalization and reverse genetic experiments to ascertain the location and role of the MtPTs in phosphate transport in roots and during the AM symbiosis.

\section{MATERIALS AND METHODS}

Plant growth and mycorrhizal colonization procedures.

Stock cultures of $G$. versiforme were prepared and maintained according to Harrison and Dixon (1993). The M. truncatula lines, growth and colonization procedures, and time course experiment were set up as described previously (Harrison and Dixon 1993). Briefly, 2-week-old seedlings (7 to 10 plants per $11-\mathrm{cm}$ pot) were inoculated with 5,000 spores 
from G. versiforme sporocarps. Control plants were mock inoculated with the final, distilled water wash from the sterilization procedure. The plants were fertilized weekly with halfstrength Hoagland's (Arnon and Hoagland 1940) solution containing $20 \mu \mathrm{M}$ phosphate. The roots were harvested 8,15 , 22, 29, and 44 dai, and colonization levels were assessed as described previously (Harrison and Dixon 1993). Colonization levels at $8,15,22,29$, and 44 dai were $12,20,57,71$, and $72 \%$ of the root length, respectively.

\section{Growth of $M$. truncatula under varying phosphate regimes.}

M. truncatula seedlings (14 days old) were grown on presterilized sand in $11-\mathrm{cm}$ pots. Each pot contained 7 to 10 seedlings. Pots were watered three times a week with halfstrength Hoagland's solution containing either 0, 0.02, 0.1, 1.0 , or $5.0 \mathrm{mM} \mathrm{KH} \mathrm{PO}_{4}$. Levels of potassium were maintained by addition of the appropriate amount of $\mathrm{K}_{2} \mathrm{SO}_{4}$. After 46 days of growth under these treatments the plants were harvested and the tissue frozen for Northern blot and phosphate analysis (Ames 1966). The phosphate levels in the leaves of plants were $3.96 \times 10^{-3}, 8.65 \times 10^{-3}, 17.03 \times 10^{-3}, 29.75 \times 10^{-3}$, and $74.36 \times 10^{-3} \mu \mathrm{mol}$ per $\mathrm{mg}$ of dry tissue for the $0,0.02,0.1$,

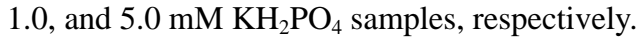

\section{Liquid culture of $M$. truncatula seedlings.}

Sterilized seeds were germinated on $0.8 \%$ (wt/vol) water agar and 10 seedlings were transferred to 1-liter flasks containing $300 \mathrm{ml}$ of Murishage-Skoog (MS) medium (1.25 mM $\mathrm{KH}_{2} \mathrm{PO}_{4}$ ). The flasks were placed on a G10 gyratory shaker (New Brunswick Scientific, Edison, NJ) at $136 \mathrm{rpm}$. After 4 days, the seedlings were rinsed twice with $200 \mathrm{ml}$ of sterilized, double-distilled water and then transferred to $300 \mathrm{ml}$ of MS medium either lacking $\mathrm{KH}_{2} \mathrm{PO}_{4}$, or containing 1.25 or $2.50 \mathrm{mM} \mathrm{KH} \mathrm{PO}_{4}\left(\mathrm{~K}_{2} \mathrm{SO}_{4}\right.$ was used to replace the $\mathrm{KH}_{2} \mathrm{PO}_{4}$ to maintain a constant potassium level). The seedlings were grown for an additional 7 days before harvest.

\section{Isolation of phosphate transporter cDNA clones.}

Root cDNA libraries prepared from $M$. truncatula and $M$. truncatula colonized with $G$. versiforme were screened according to standard procedures (Sambrook et al. 1989; Burleigh and Harrison 1997). The EcoRI fragment of an A. thaliana EST clone (stock no. 134M11T7) was used as a probe. Final filter washing conditions were $2 \times$ SSPE (1× SSPE is $0.15 \mathrm{M} \mathrm{NaCl}, 10 \mathrm{mM} \mathrm{NaPO}_{4}$, and $1 \mathrm{mM}$ EDTA [pH 7.4]), $2 \%$ sodium dodecyl sulfate (SDS) at $65^{\circ} \mathrm{C}$. The clones were sequenced by dideoxy sequencing on an ABI 373A automated DNA sequencer (Applied Biosystems, Foster City, CA). A PstI fragment from MtPT1 (1,386 bp) was used to screen the cDNA libraries to obtain the partial clones of MtPT2.

\section{Southern blot analysis.}

Genomic DNA was extracted from $M$. truncatula leaves by the method of Dellaporta et al. (1983). Southern blots were prepared and hybridized by standard protocols (Church and Gilbert 1984). [ $\left.\alpha-{ }^{32} \mathrm{P}\right]$-dATP-labeled probes were prepared by random primed labeling according to Feinberg and Vogelstein (1983). The PstI fragment from MtPT1 was used as a probe on the genomic Southern blots.

\section{Northern blot analysis.}

Total RNA was extracted according to Chromczynski and Sacchi (1987). Northern blots were prepared and hybridized according to standard protocols (Genescreen manual, NEN, Beverly, MA). The Northern blots shown in each figure were sequentially stripped and reprobed with the probes indicated at the right hand side of each figure. Transcripts were visualized and quantified by phosphoimage analysis (Molecular Dynamics phosphoimager SF, Sunnyvale, CA) and the MtPT transcript levels were normalized relative to the rRNA controls. The transcript levels described in the text are normalized levels. The PA phosphatase cDNA clone from A. thaliana was a kind gift from T. McKnight (Department of Biology, Texas A\&M University, College Station). The cDNA insert was excised by digestion with $B g l \mathrm{II}$ and $\mathrm{SacI}$. Final washing was performed according to Church and Gilbert (1984). On all Northern blots an 18S rRNA probe prepared from pSR1-2B3 (Eckenrode et al. 1985) was used as control to check for equal loading and transfer.

\section{Oligonucleotide probes and hybridization procedures.}

To investigate the individual expression of MtPT1 and MtPT2, oligos MtPT1, 5'-GTATTGATTCTTACAACCAAGA AGCATAGGACTGCATC-3' (complementary to the 3'-UTR of MtPT1) and MtPT2, 5'-CTTGTGAGAAGTCAAGTT TGTATGAGGAGCTAGCTAGG-3' (complementary to the 5'-UTR of MtPT2) were used as probes for hybridization. Oligonucleotides were labeled with $\left[\gamma^{32} \mathrm{P}\right]-\mathrm{ATP}$ and the procedures for prehybridization and hybridization were performed according to Sambrook et al. (1989). The blots were washed with $2 \times \mathrm{SSPE}, 2 \% \mathrm{SDS}$ at $25^{\circ} \mathrm{C}$ below theoretical $\mathrm{T}_{\mathrm{m}}$. The specificity of the oligo under the above conditions was determined by hybridization to the individual plasmid clones (data not shown).

\section{Expression in $S$. cerevisiae and phosphate uptake studies.}

MtPT1 primers with the sequences 5'-CGGGATCCAAG CTTATGTCTGGAGAATTAGG-3' and 5'-CCCAAGCTTTC AAGCTACATTTTCAAAC-3' were used to amplify MtPT1 from the MtPT1 plasmid by polymerase chain reaction (PCR) with Vent DNA polymerase (New England Biolabs, LOCATION). These primers contained HindIII sites at their $3^{\prime}$ ends to facilitate cloning into the expression vector. The PCR product was gel-purified, cut with HindIII, and cloned into the HindIII site of yeast expression vector pAAH5 (Ammerer 1983). This construct and pAAH5 were transformed into the yeast strain NS219 by the lithium acetate method (Ito et al. 1983). Phosphate uptake assays with ${ }^{33} \mathrm{Pi}$ were performed according to Ueda and Oshima (1975). The $K_{m}$ and $V_{\max }$ of MtPT1 were calculated as described (Eisenthal and CornishBowden 1974). Uptake experiments were performed in duplicate and data are the result of at least two experiments.

\section{ACKNOWLEDGMENTS}

We thank T. McKnight (Department of Biology, Texas A\&M University, College Station) for the purple acid phosphatase cDNA clone, R. Gonzales and Y. Bao for critical reviews of the manuscript, and members of the Plant Biology Division for helpful discussions. This work was supported by The Samuel Roberts Noble Foundation. 


\section{LITERATURE CITED}

Alexander, T., Meier, R., Toth, R., and Weber, H. C. 1988. Dynamics of arbuscule development and degeneration in mycorrhizas of Triticum aestivum L. and Avena sativa L. with reference to Zea mays L. New Phytol. 110:363-370.

Ames, B. N. 1966. Assay of inorganic phosphate, total phosphate and phosphatases. Methods Enzymol. 8:115-118.

Ammerer, G. 1983. Expression of genes in yeast using the ADCI promoter. Methods Enzymol. 101:192-201.

Arnon, D. I., and Hoagland, D. R. 1940. Crop production in artificial culture solutions and in soils with special reference to factors influencing yields and absorption of inorganic nutrients. Soil Sci. 50:463483.

Beever, R. E., and Burns, D. J. W. 1980. Phosphorus uptake, storage and utilization by fungi. Adv. Bot. Res. 127-129.

Bun-ya, M., Harashima, S., and Oshima, Y. 1992. Putative GTP-binding protein, Gtrl, associated with the function of the Pho84 inorganic phosphate transporter in Saccharomyces cerevisiae. Mol. Cell. Biol. 12:2958-2966.

Bun-ya, M., Nishimura, M., Harashima, S., and Oshima, Y. 1991. The PHO84 gene of Saccharomyces cerevisiae encodes an inorganic phosphate transporter. Mol. Cell. Biol. 11:3229-3238.

Bun-ya, M., Shikata, K., Nakade, S., Yompakdee, C., Harashima, S., and Oshima, Y. 1996. Two new genes, PHO86 and PHO87, involved in inorganic phosphate uptake in Saccharomyces cerevisiae. Curr. Genet. 29:344-351.

Burleigh, S. H., and Harrison, M. J. 1997. A novel gene whose expression in Medicago truncatula roots is suppressed in response to colonization by vesicular-arbuscular mycorrhizal (VAM) fungi and to phosphate nutrition. Plant Mol. Biol. 34:199-208.

Chromczynski, P., and Sacchi, N. 1987. Single-step method of RNA isolation by acid guanidinium thiocyanate-phenol-chloroform extraction. Anal. Biochem. 162:156-159.

Church, G. M., and Gilbert, W. 1984. Genomic sequencing. Proc. Natl. Acad. Sci. USA 81:1991-1995.

Clarkson, D. T., and Lüttge, U. 1991. Mineral nutrition: Inducible and repressible nutrient transport systems. Prog. Bot. 52:61-83.

Cogliatti, H. H., and Clarkson, D. T. 1983. Physiological changes in, and phosphate uptake by potato plants during development of, and recovery from phosphate deficiency. Physiol. Plant. 58:287-294.

Cox, G., and Tinker, P. B. 1976. Translocation and transfer of nutrients in vesicular-arbuscular mycorrhizas. I. The arbuscule and phosphorus transfer: A quantitative ultrastructural study. New Phytol. 77:371-378.

Dellaporta, S. L., Wood, J., and Hicks, J. B. 1983. A plant DNA minipreparation. Plant Mol. Biol. Rep. 1:19-22.

Dunlop, J., and Gardiner, S. 1983. Phosphate uptake, proton extrusion and membrane electropotentials of phosphorus deficient Trifolium repens. J. Exp. Bot. 44:1801-1808.

Eckenrode, V. K., Arnold, J., and Meagher, R. B. 1985. Comparison of the nucleotide sequence of soybean 18S rRNA with the sequence of other small subunit rRNAs. J. Mol. Evol. 21:259-269.

Eisenthal, R., and Cornish-Bowden, A. 1974. The direct linear plot. A new graphical procedure for estimating enzyme kinetic parameters. Biochem. J. 139:715-720.

Feinberg, A. P., and Vogelstein, B. 1983. A technique for radiolabeling DNA restriction endonuclease fragments to high specific activity. Anal. Biochem. 132:6-13.

Furihata, T., Suzuki, M., and Sakurai, H. 1992. Kinetic characterization of two phosphate-uptake systems with different affinities in suspension-cultured Catharanthus roseus protoplasts. Plant Cell Physiol. 33: 1151-1157.

Gianinazzi-Pearson, V., Smith, S. E., Gianinazzi, S., and Smith, F. A. 1991. Enzymatic studies on the metabolism of vesicular-arbuscular mycorrhizas. New Phytol. 117:61-74.

Griffith, J. K., Baker, M. E., Rouch, D. A., Page, M. G. P., Skurray, R A., Paulsen, I. T., Chater, K. F., Baldwin, S. A., and Henderson, P. J. F. 1992. Membrane transport proteins: Implications of sequence comparisons. Curr. Opin. Cell Biol. 4:684-695.

Harley, J. L., and Smith, S. E. 1983. Mycorrhizal Symbiosis. Academic Press, London.

Harrison, M. J. 1996. A sugar transporter from Medicago truncatula: Altered expression pattern in roots during vesicular-arbuscular (VA) mycorrhizal associations. Plant J. 9:491-503.
Harrison, M. J., and Dixon, R. A. 1993. Isoflavonoid accumulation and expression of defense gene transcripts during the establishment of vesicular-arbuscular mycorrhizal associations in roots of Medicago truncatula. Mol. Plant-Microbe Interact. 6:643-654.

Harrison, M. J., and van Buuren, M. L. 1995. A phosphate transporter from the mycorrhizal fungus Glomus versiforme. Nature 378:626-629.

Ito, H., Fukuda, Y., Murata, K., and Kimura, A. 1983. Transformation of intact yeast cells treated with alkali cations. J. Bacteriol. 153:163-168.

Johnson, K. D., and Chrispeels, M. J. 1992. Tonoplast-bound protein kinase phosphorylates tonoplast intrinsic protein. Plant Physiol. 100: 1787-1795.

Lawrence J. C., Jr., Hiken, J. F., and James, D. E. 1990. Phosphorylation of the glucose transporter in rat adipocytes. Identification of the intracellular domain at the carboxyl terminus as a target for phosphorylation in intact cells and in vitro. J. Biol. Chem. 265:2324-2332.

Leggewie, G., Willmitzer, L., and Riesmeier, J. W. 1997. Two cDNAs from potato are able to complement a phosphate uptake-deficient yeast mutant: Identification of phosphate transporters from higher plants. Plant Cell 9:381-392.

Marger, M. D., and Saier, M. H., Jr. 1993. A major superfamily of transmembrane facilitators that catalyze uniport, symport and antiport. Trends Biochem. Sci. 18:13-20.

Marschner, H. 1995. Nutrient availability in soils. Pages 483-507 in: Mineral Nutrition of Higher Plants. H. Marschner, ed. Academic Press, London.

Marx, C., Dexheimer, J., Gianinazzi-Pearson, V., and Gianinazzi, S. 1982. Enzymatic studies on the metabolism of vesicular-arbuscular mycorrhizas. IV. Ultracytoenzymological evidence (ATPase) for active transfer processes in the host-arbuscule interface. New Phytol. 90: 37-43.

Maurel, C., Kado, R. T., Guern, J., and Chrispeels, M. J. 1995. Phosphorylation regulates the water channel activity of the seed-specific aquaporin alpha-Tip. EMBO J. 14:3028-3035.

Muchhal, U. S., Pardo, J. M., and Raghathama, K. G. 1996. Phosphate transporters from the higher plant Arabidopsis thaliana. Proc. Natl. Acad. Sci. USA 93:10519-10523.

Nandi, S. K., Pant, R. C., and Nissen, P. 1987. Multiphasic uptake of phosphate by corn roots. Plant Cell Environ. 10:463-474.

Patel, K., Lockless, S., Thomas, B., and McKnight, T. 1997. A secreted purple acid phosphatase from Arabidopsis. Plant Physiol. (suppl.) 111:81.

Pearson, J. N., and Jakobsen, I. 1993. The relative contribution of hyphae and roots to phosphorus uptake by arbuscular mycorrhizal plants, measured by dual labelling with ${ }^{32} \mathrm{P}$ and ${ }^{33} \mathrm{P}$. New Phytol. 124: 489-494.

Remy, W., Taylor, T. N., Hass, H., and Kerp, H. 1994. Four hundredmillion-year-old vesicular arbuscular mycorrhizae. Proc. Natl. Acad Sci. USA 91:11841-11843.

Sambrook, J., Fritsch, E. F., and Maniatis, T. A. 1989. Molecular Cloning: A Laboratory Manual. 2nd ed. Cold Spring Harbor Laboratory, Cold Spring Harbor, NY.

Sanders, F. E., and Tinker, P. B. 1971. Mechanism of absorption of phosphate from soil by Endogone mycorrhizas. Nature 233:278-279.

Shimogawara, K., and Usuda, H. 1995. Uptake of inorganic phosphate by suspension-cultured tobacco cells: Kinetics and regulation by $\mathrm{Pi}$ starvation. Plant Cell Physiol. 36:341-351.

Simon, L., Bousquet, J., Lévesque, R. C., and Lalonde, M. 1993. Origin and diversification of endomycorrhizal fungi and coincidence with vascular land plants. Nature 363:67-69.

Smith, F. A., and Smith, S. E. 1989. Membrane transport at the biotrophic interface: An overview. Aust. J. Plant Physiol. 16:33-43.

Smith, F. A., and Smith, S. E. 1996. Mutualism and parasitism: Diversity in function and structure in the "arbuscular" (VA) mycorrhizal symbiosis. Adv. Bot. Res. 22:1-43.

Smith, F. W., Ealing, P. M., Dong, B., and Delhaize, E. 1997. The cloning of two Arabidopsis genes belonging to a phosphate transporter family. Plant J. 11:83-92.

Smith, S. E., and Gianinazzi-Pearson, V. 1988. Physiological interactions between symbionts in vesicular-arbuscular mycorrhizal plants. Annu. Rev. Plant Physiol. Plant Mol. Biol. 39:221-244.

Smith, S. E., and Smith, F. A. 1990. Structure and function of the interfaces in biotrophic symbioses as they relate to nutrient transport. New Phytol. 114:1-38.

Ueda, Y., and Oshima, Y. 1975. A constitutive mutation, phoT, of the 
repressible acid phosphatase synthesis with inability to transport inorganic phosphate in Saccharomyces cerevisiae. Mol. Gen. Genet. 136: 255-259.

Versaw, W. K. 1995. A phosphate-repressible, high-affinity phosphate permease is encoded by the pho- $5^{+}$gene of Neurospora crassa. Gene $153: 135-139$

Yompakdee, C., Bun-ya, M., Shikata, K., Ogawa, N., Harashima, S., and
Oshima, Y. 1996a. A putative new membrane protein, Pho86p, in the inorganic phosphate uptake system of Saccharomyces cerevisiae. Gene 171:41-47.

Yompakdee, C., Ogawa, N., Harashima, S., and Oshima, Y. 1996b. A putative membrane protein, Pho88p, involved in inorganic phosphate transport in Saccharomyces cerevisiae. Mol. Gen. Genet. 251:580590. 